\title{
To Compare the Exogenous Human Chorionic Gonadotropin Trigger with Endogenous Leutinizing Hormone Surge in Ultrasound Monitored Cycles for Timing of Intrauterine Insemination in Women with Unexplained Infertility
}

\author{
Anuradha Singh ${ }^{1}$, Gyaneshowari Leishram², Manju Puri ${ }^{3}$
}

\begin{abstract}
Aim: To compare rates of follicular rupture after human chorionic gonadotropin (hCG) trigger with after spontaneous leutinizing hormone (LH) surge in women undergoing controlled ovarian stimulation (COS) and intrauterine insemination (IUI). To observe any findings suggestive of premature LH surge in $\mathrm{hCG}$ triggered cycles and compare the pregnancy rates in the two groups.

Materials and methods: A total of thirty-three women with unexplained infertility were enrolled. Women were subjected to $\operatorname{COS}$ with injection follicle stimulating hormone (FSH) 75IU I/M for 5 days. A total of 100 cycles were studied. The cycles were divided in to two groups. In group I, ultrasound monitoring was done from day 8 till follicle size of $18 \mathrm{~mm}$ followed by trigger with injection hCG 5,000 IU followed by IUI after 36-48 hours of injection hCG. Group II cycles were followed with ultrasound till follicle size $14 \mathrm{~mm}$ and urinary LH surge test was done till it turned positive. Ultrasound was done after 24 hours of positive test and then IUI. The two groups were compared about the proportion of cycles with documented rupture of follicle. The pregnancy rates and presence of features suggestive of premature luteinization in $\mathrm{hCG}$ triggered cycles were studied .

Results: The mean time of follicular rupture was $43 \pm 8.32$ hours in group I from hCG trigger and $27.77 \pm 8.69$ hours in group II from positive LH surge. The difference between number of cycles with documented follicular rupture and mean day of IUI was not significant in the two groups $(95.35 \%$ vs $85.58 \%)$. The pregnancy rate was higher in group II than group I (11.6\% vs $7.3 \%)$ but the difference was not significant statistically. Conclusion: Adequately powered studies are required to support the preference of endogenous $\mathrm{LH}$ surge to exogenous LH surge (hCG trigger) for timing of IUI.

Clinical significance: To compare exogenous LH surge (hCG trigger) with endogenous LH surge to for timing of IUI in unexplained infertility. Keywords: Infertility, Pregnancy, Ultrasonography.

International Journal of Infertility and Fetal Medicine (2019): 10.5005/jp-journals-10016-1178
\end{abstract}

\section{INTRODUCTION}

Infertility is the most common gynecological problem affecting the women of reproductive age group. Of all causes of infertility, unexplained infertility constitutes $10-20 \% .^{1}$ Unexplained infertility is defined as infertility where all standard investigations of infertility are normal, that is ovulation is documented on USG, tubal patency is confirmed on HSG or diagnostic laparoscopy and semen analysis is normal. Out of different treatment options which are available for this subgroup of infertile women, controlled ovarian stimulation and IUI are most commonly used first line treatment. Given the lifespan of ovum of 12-24 hours accurate timing of IUI is important. It is determined either by detection of $\mathrm{LH}$ surge or by giving $\mathrm{hCG}$ injection and is likely to affect the success rate of IUI. In hCG triggered cycles spontaneous premature LH surge before dominant follicle reaches the size of $18 \mathrm{~mm}$ is another factor likely to affect the success rates of ovarian stimulation and IUI in unexplained infertility. It is observed in $25-30 \%$ of stimulated IUI cycles. Various studies have been conducted to study comparing different methods to time IUI with ovulation with varied results. Some studies have shown of $\mathrm{LH}$ surge testing to be better than hCG trigger because endogenous surge would happen when the oocyte is mature to be released whereas in exogenous trigger at a follicle size of $16-18 \mathrm{~mm}$ the oocyte may not be always mature. ${ }^{2}$ This study was planned with the primary objective to compare rates of follicular rupture after hCG trigger

\begin{abstract}
1,2Department of Obstetrics and Gynaecology, Lady Hardinge Medical College, New Delhi, India

${ }^{3}$ Department of Obstetrics and Gynaecology, Lady Hardinge Medical College and Smt Sucheta Kriplani Hospital, New Delhi, India

Corresponding Author: Anuradha Singh, Department of Obstetrics and Gynaecology, Lady Hardinge Medical College, New Delhi, India, Phone: +919891387779, e-mail: sbxy@rediffmail.com

How to cite this article: Singh A, Leishram G, Puri M. To Compare the Exogenous Human Chorionic Gonadotropin Trigger with Endogenous Leutinizing Hormone Surge in Ultrasound Monitored Cycles for Timing of Intrauterine Insemination in Women with Unexplained Infertility. Int J Infertil Fetal Med 2019;10(1):8-11.
\end{abstract}

Source of support: Nil

Conflict of interest: None

with that after spontaneous LH surge in women undergoing COS and IUI. The secondary objectives were to observe any ultrasonic findings suggestive of premature LH surge in hCG triggered cycles and compare the pregnancy rates in the two groups.

\section{Materials and Methods (Flowchart 1)}

This RCT was conducted in the Department of Obstetrics and Gynecology at LHMC from 1st November 2013 to 31st March 2015. All patients attending the infertility clinic in SSKH were subjected to 
Flowchart 1: Study design

Study design

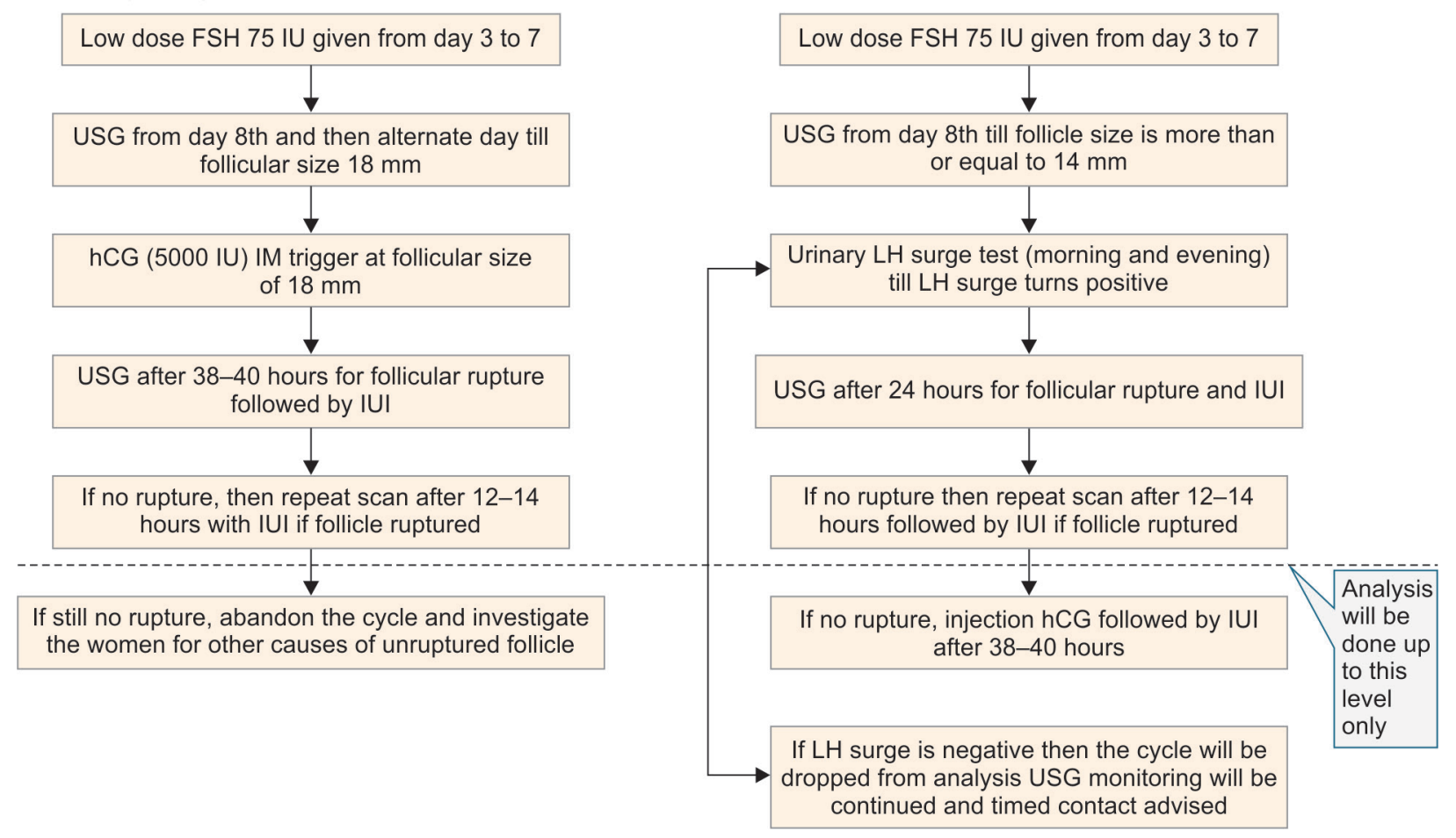

a basic workup of infertility. Detailed history, physical examination and baseline investigations of infertility were done and 33 women with unexplained infertility were enrolled in the study after written informed consent. A baseline USG was done on day 2 of menstrual cycle and women were subjected to controlled ovarian stimulation with injection FSH $75 \mathrm{IU}$ I/M for 5 days starting from day 3 of menses. The cycles were randomly divided by computer generated numbers into two groups of 50 cycles each. In group I ultrasound monitoring was done on every alternate day starting from day 8 till follicle reached a size of $18 \mathrm{~mm}$ followed by trigger with injection hCG 5,000 IU. IUI was done 36-48 hours of inj. hCG after documenting rupture of follicle. In group II, cycles were followed with serial ultrasound till follicle reached a size of $14 \mathrm{~mm}$ when woman was advised to do urinary LH surge test (I-sure) twice a day till it turned positive. This was followed by USG after 24 hours of positive LH test and IUI if the follicle rupture was documented. The groups were compared for the proportion of women with documented rupture of follicle in the two groups. The pregnancy rates and presence of ultrasonic features suggest possibly of premature luteinization in hCG triggered cycles. The results were analyzed by SPSS software system.

The $t$ test, Fisher's exact test were used to calculate $p$ value.

\section{Results}

In group I, out of 50 cycles, 43 were monitored completely and in group II, 48 were completely monitored. In rest cycles either there was no dominant follicles, so cycles were abandoned or patients were lost to follow-up (Flowchart 2).

In this study mean age of the women was $26.78 \pm 1.3$ years with mean duration of infertility as $5.05 \pm 3.9$ years. The two groups were comparable in terms of age and duration of infertility. The antral follicle count in group I and group II was $8.8 \pm 0.89$ and $8.9 \pm 0.91$, respectively and was not statistically different. No. of dominant follicles on day 10 ranged from 1 to 4 in both groups. The mean endometrial thickness (ET) on day 8 was $6.52 \pm 1.4 \mathrm{~mm}$ in group I and $6.73 \pm 0.6$ in group II. On day 10 mean ET was $7.8 \pm 0.87 \mathrm{~mm}$ and $7.9 \pm 0.8 \mathrm{~mm}$ in group I and group II, respectively. Mean ET on day of positive LH surge and day of hCG trigger was $8.8 \pm 0.51$ and $8.3 \pm 0.73$, respectively. The difference was not statistically significant. The mean time of follicular rupture was $43 \pm 8.32$ hours from administration of hCG trigger in group I (Fig. 1) and $27.77 \pm$ 8.69 hours in group II from positive LH surge (Fig. 2). The rate of follicular rupture was $95.50 \%$ in group I and $89.58 \%$ in group II (Fig. 3), however this difference was not statistically significant. In $21.95 \%$ cycles in group I there was evidence of premature luteinization evident by conversion of the pattern of endometrium from follicular (triple line) to secretory (echogenic) before the trigger was administered. Group I had a lower pregnancy rate $7.3 \%$ per cycle, compared to $11.6 \%$ in group II but the difference was not statistical significant (Fig. 4).

\section{Discussion}

In group I follicular rupture after hCG trigger was observed within 36-48 hours in majority $(76.2 \%)$ of cycles, thereby increasing the chances of ovum to get fertilized. Mean follicular time of rupture was $43 \pm 8.32$ hours. Testart and Frydman suggested that follicular rupture usually occurs 36-48 hours after hCG administration, which was in accordance in our study. Many different time intervals have been suggested for IUI. Interval between 12 hours and 60 hours have been recommended in various studies. ${ }^{4}$ Preyer et al. have suggested that interval between 36 hours and 40 hours yield higher pregnancy rate than 32-34 hours.

In group II 70.8\% of cycles had follicular rupture within 24 hours of positive LH surge and no rupture was seen in $10.4 \%$ of cycles till day 20. Ovulation can occur within wide time period of 24-56 hours 
Flowchart 2: Results of study

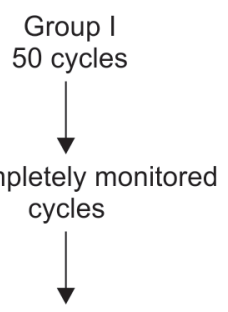

42 cycles with ruptured follicle 1 with unruptured follicle

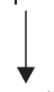

3 cycles conception occurred $(7.3 \%)$ (out of 42 )

38 cycles-no conception

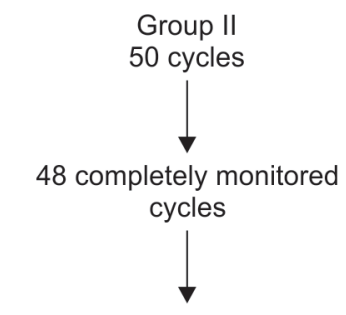

43 cycles with ruptured follicle 5 cycles with unruptured follicle

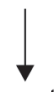

5 cycles conception occured (out of 43)

38 cycles-no conception

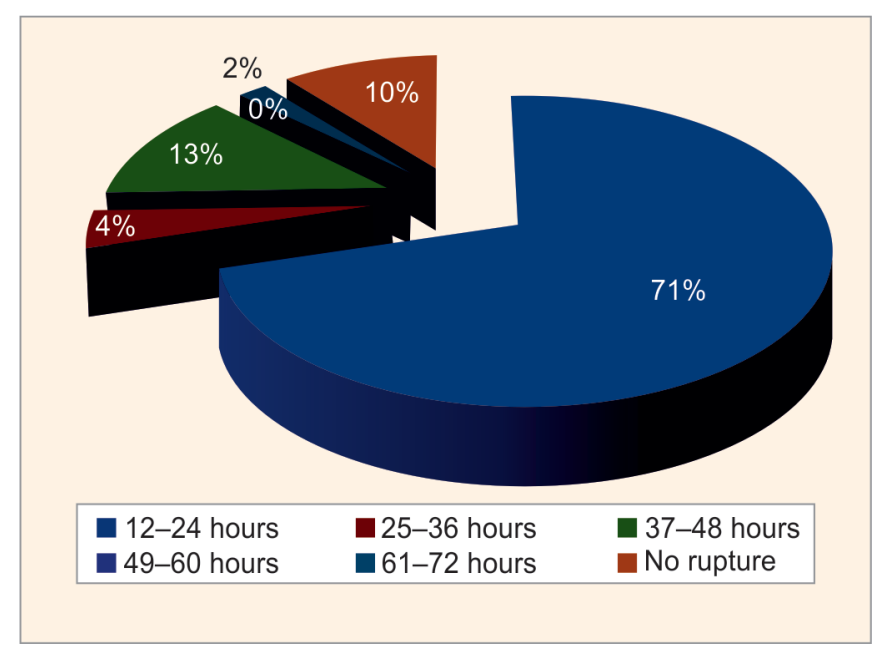

Fig. 2: Time of documented follicular rupture in group II (LH surge detection)

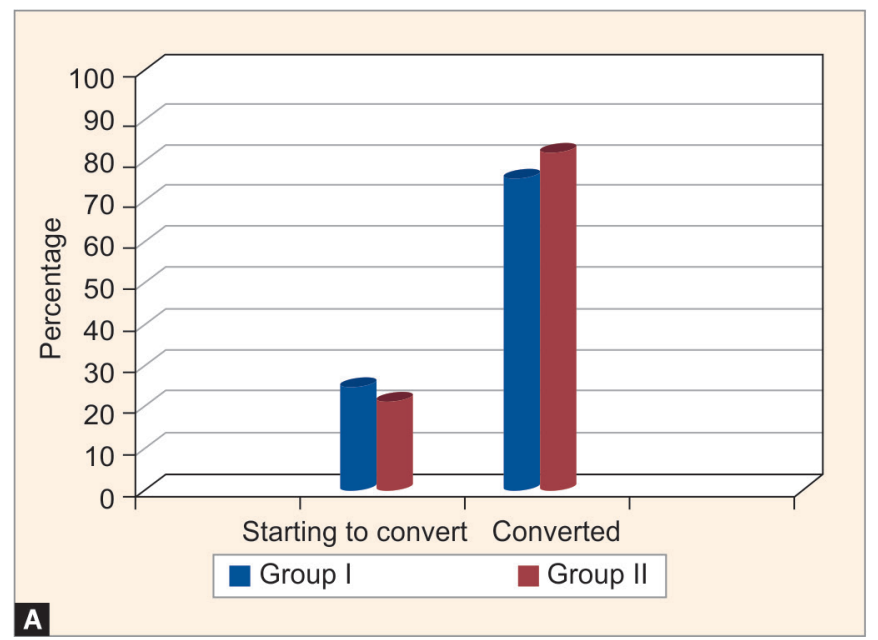

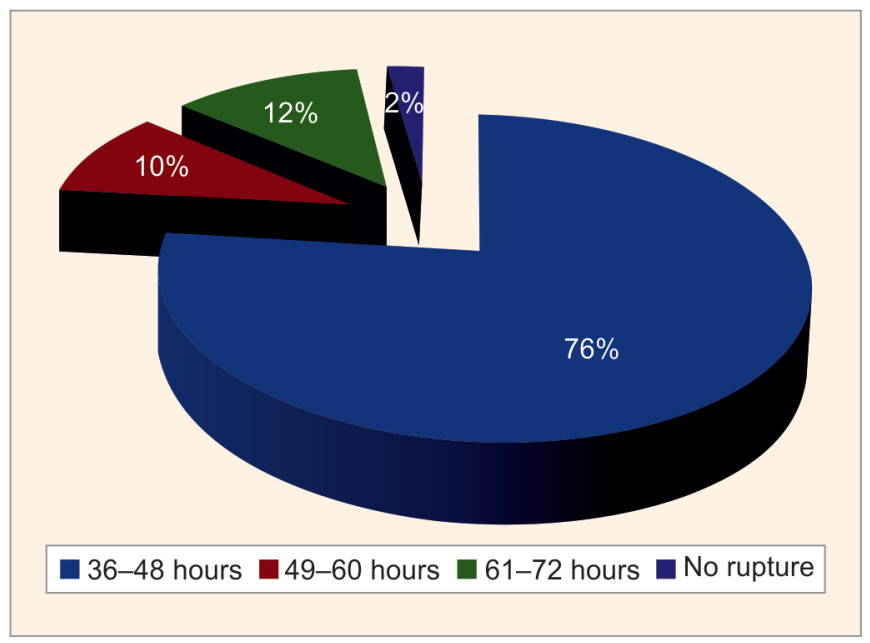

Fig. 1: Time of documentation of follicular rupture in group I

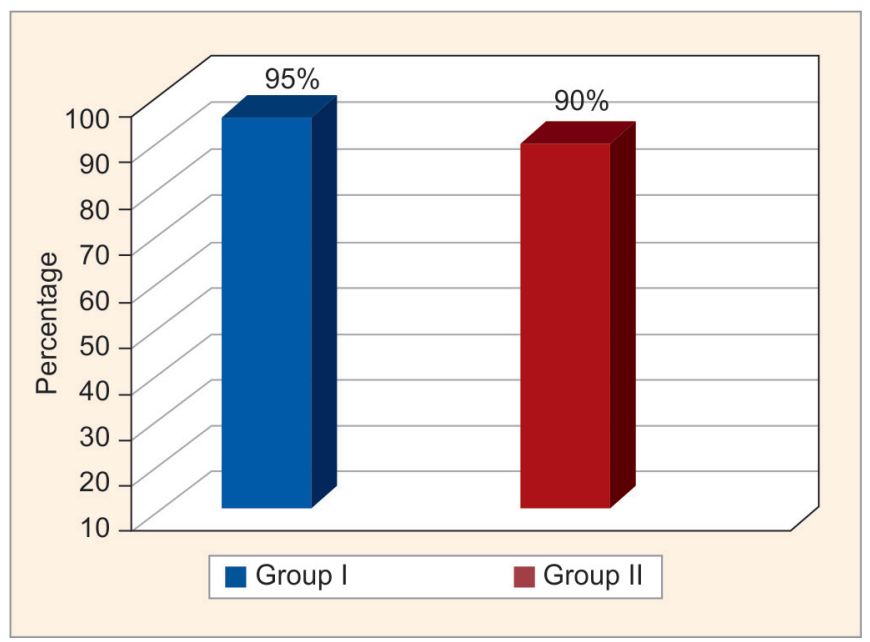

Fig. 3: Endometrial pattern in day of IUI in group I and II

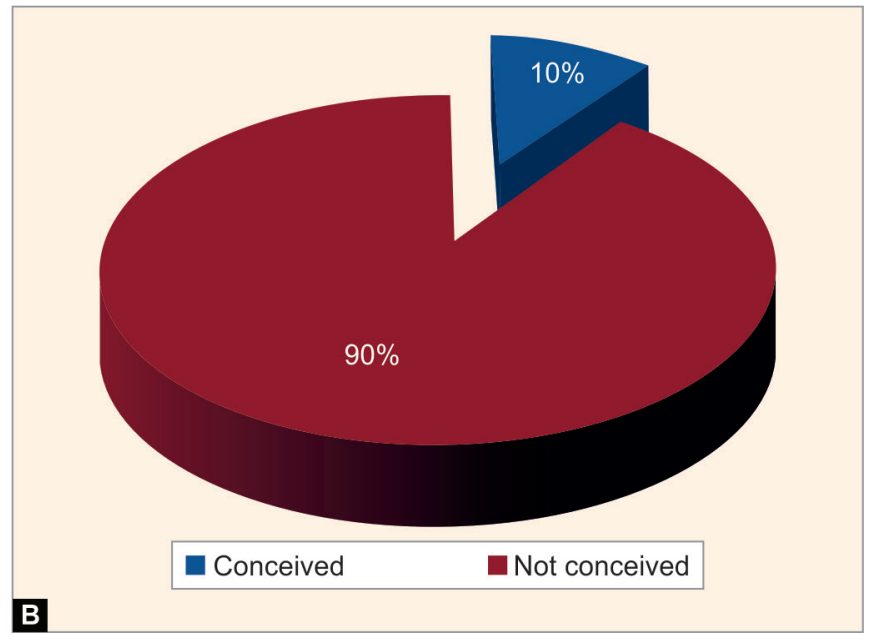

Figs 4A and B: (A) Proportion of cycles with follicular rupture in group I and group II; (B) Pregnancy rate per cycle

after the onset of LH surge. In a study done by Martinez et al. ${ }^{5}$ in 1994 on timing of IUI, showed that most ovulation occurring between 16 hours and 28 hours after positive LH test and better result will be obtained if IUI was carried out in $24 \pm 6$ hours after positive test.
Endometrial lining on day of hCG injection was triple layered in $35.7 \%$, starting to convert in $42.90 \%$ and converted in $21.95 \%$, suggestive of premature and early ovulation. IUI done 36-40 hours after injection hCG in this group of premature LH surge, may be late. Hence poor timing of IUI lowered the success rate 
of conception, due to nonavailability of ovum for fertilization and decreasing the receptivity of endometrium for fertilization. Endometrial lining was converted on day of IUI in $73.2 \%$ in group I and $79.1 \%$ in group II and started to convert on day of IUI in $26.3 \%$ and $20.9 \%$ in group I and group II, respectively. In natural insemination sperms are available for fertilization 48-72 hours after intercourse. IUI by-passes the cervix and sperms are not stored so there is need for proper timing of IUI so that ova are available for fertilization at the time of IUI.

Kyrou et al. ${ }^{2}$ in 2012 did a prospective randomized study to assess when spontaneous triggering of ovulation by detecting $\mathrm{LH}$ rise with serial serum testing, results in higher pregnancy rate as compared to administration of hCG in patients undergoing IUI in natural cycles. In this study it was found that duration of follicular phase was significantly higher in spontaneous LH group as compared to hCG group ( $p$ value 0.004). Ongoing pregnancy rates were also higher in spontaneous LH group (34/150 vs 16/150), $p$ 0.08. They concluded that use of LH kits for timing ovulation in natural cycles might be the best way to maximize the proportion of pregnancy for pts undergoing IUI.

In our study pregnancy rate per cycle was $10 \%$. A total of 8 women conceived. The pregnancy rates were higher in group II $11.6 \%$ compared to $7.3 \%$ in group I, but difference was statistically insignificant. Similar findings were obtained by the study done by Khattab et al., ${ }^{6}$ where higher pregnancy rates were achieved when IUI was performed 24-42 hours after positive LH surge ( $11.7 \%$ vs $5.6 \%)$. Zriet et al. in their study also showed that expensive and time-consuming methods such as ultrasound monitoring of follicular development and hCG induced ovulation do not appear to produce an increase in pregnancy rate over LH monitoring of ovulation which was in accordance with our study. However, a study done by Kyrou et al., ${ }^{2}$ ongoing pregnancy rate was significantly higher in spontaneous LH group as compared to hCG group (34/150 vs $16 / 150)$. However, in a recent similar study was done by Edward Hughes et al. in 2017,3 in $365 \mathrm{COH}$ cycles to evaluate whether clinical pregnancy rate is affected by timing IUI, according to serum $\mathrm{LH}$ surge and hCG trigger for patients with variety of infertility etiologies. It was found that administration of hCG prior to IUI resulted in higher clinical pregnancy rates compared with serum LH surge: $18.2 \%$ vs $5.8 \%, p=0.012$. It was also observed that patients in whom hCG was administered concurrently with serum LH surge had a higher pregnancy rate than $\mathrm{hCG}$ trigger group.

A recent study was done by $\mathrm{El} \mathrm{Hachem} \mathrm{et}$ al. $^{8}$ to assess whether therapeutic donor inseminations in natural cycles using ultrasound monitoring and ovulation trigger by hCG improves the live birth rate, when compared with the detection of $\mathrm{LH}$ surge using urinary kits. It was observed that cumulative live birth rates were comparable between two groups (31.4\% vs $21 \%$ ). They also concluded that urinary LH monitoring was as effective as ultrasound monitoring and ovulation trigger with hCG in therapeutic inseminations.

In a Cochrane review in 2014, ${ }^{7}$ ten RCTs comparing different methods of timing of IUI were evaluated. They found no difference in live birth rates between hCG and LH surge. This review concluded that there is no evidence to advise one treatment option over another (ultrasound with hCG injection vs urinary LH surge detection), since live birth rates and pregnancy rates do not differ.

\section{Conclusion}

This study was conducted to compare hCG trigger with spontaneous LH hormonal surge for timing of IUI in unexplained infertility patients. It was observed that in hCG group mean time of follicular rupture was $43.1 \pm 8.32$ hours which is like studies by various authors. ${ }^{9,10}$ In group II it was $27.77 \pm 8.69$ hours that was compared well with the time range observed by various authors. ${ }^{11,12}$ Overall pregnancy rates were $10 \%$ in study however difference was comparable between two groups. However, size of each groups was too small for results to be statistically significant. More robust studies are required to support the preference of endogenous LH surge with exogenous LH surge (hCG trigger) for timing of IUI. Till then the choice should be made mainly based on hospital facilities, convenience of patient and cost factor.

\section{References}

1. Aubuchom M, Burney RO, Schust DJ, et al. Infertility and assisted reproductive technique. In: Berek JS, ed. Berek and Novak's Gynaecology, 15th ed., New Delhi: Wolters Klumer India Pvt. Ltd; 2011. pp. 1133-1189.

2. Kyrou D, Kolibianakis EM, Fatemi HM, et al. Spontaneous triggering of ovulation versus HCG administration in patients undergoing IUI: a prospective randomized study. Reprod Biomed Online 2012;25(3):278-283. DOI: 10.1016/j.rbmo.2012.05.005.

3. Taerk E, Hughes E, Greenberg C, et al. Controlled ovarian hyperstimulation with intrauterine insemination is more successful after r-hCG administration than spontaneous LH surge. J Reprod Infertil 2017;18(3):316-322.

4. Fuh KW, Wang $X$, Tai A, et al. Intrauterine insemination: effect of the temporal relationship between the luteinizing hormone surge, human chorionic gonadotrophin administration and insemination on pregnancy rates. Hum Reprod 1997;12(10):2162-2166. DOI: 10.1093/ humrep/12.10.2162.

5. Martinez AR, Bernardus RE, Vermeiden JP, et al. Time schedules of intrauterine insemination after urinary luteinizing hormone surge detection and pregnancy results. Gynecol Endocrinol 1994;8(1):1-5. DOI: 10.3109/09513599409028450.

6. Khattab AF, Musafa FA, Taylor PJ. The use of urine LH detection kits to time IUI with donor sperm. Hum Reprod 2005;20(9):2542-2545. DOI: 10.1093/humrep/dei098.

7. Cantineau AE, Janssen MJ, Cohlen BJ, et al. Synchronised approach for intrauterine insemination in subfertile couples. Cochrane Database Syst Rev 2014;12:CD006942. DOI: 10.1002/14651858.CD006942.pub3.

8. El Hachem H, Antaki R, Sylvestre C, et al. Timing therapeutic donor inseminations in natural cycles: human chorionic gonadotrophin administration versus urinary LH monitoring. Reprod Biomed Online 2017;35(2):174-179. DOI: 10.1016/j.rbmo.2017.05.005.

9. Pellicer A, Albert C, Mercader A, et al. The follicularand endocrine environment in women with endometrioses; local and systemic cytokine production. Fertil Steril 1998;70(3):425-431. DOI: 10.1016/ S0015-0282(98)00204-0.

10. Wolff EF, Vahidi N, Alford C, et al. Influences on endometrial development during intrauterine insemination: clinical experience of 2,929 patients with unexplained infertility. Fertile Steril 2013;100(1):194-199. DOI: 10.1016/j. fertnstert 2013.03.023.

11. Nuojua Huttunton $S$, Tomas $C$, Bloigu $R$, et al. Intrauterine insemination treatment in subfertility: an analysis of factors affecting outcome. Hum Reprod 1999;14(3):698-703. DOI: 10.1093/humrep/14.3.698.

12. Edwards RG, Steptoe PC. Control of human ovulation, fertilization and implantation. Proc R Soc Med 1974;67(9):932-936. 